\title{
Late Preterm and Early Term Neonates: A New Group of High Risk Newborn in Neonatology with Varied Complications
}

Chetan Kumar, Deepak Sharma and Aakash Pandita

Department of Neonatology, Fernandez Hospital, Hyderabad, India

*Corresponding author: Deepak Sharma, Department of Neonatology, Fernandez Hospital, Hyderabad, India, Tel: +919462270002; E-mail: dr.deepak.rohtak@gmail.com

Rec date: 29 Oct 2014; Acc date: 29 Oct 2014; Pub date: 31 Oct 2014

Copyright: ( $) 2014$ Sharma D et al. This is an open-access article distributed under the terms of the Creative Commons Attribution License, which permits unrestricted use, distribution, and reproduction in any medium, provided the original author and source are credited.

\section{Introduction}

Moderate preterm, late preterm, and early term neonates are a new group of neonates which have varied complication when compared with moderate term or late term neonates. Moderate preterm and late preterm deliveries-defined, as delivery between $320 / 7$ and $336 / 7$ weeks and between $340 / 7$ and 36 6/7 weeks of gestation, respectively. The early term delivery-defined as delivery between 37 0/7 and 38 6/7 weeks, moderate term delivery between 39 0/7 and 40 6/7 weeks, late term delivery between $410 / 7$ and $416 / 7$ weeks. The post term defined as $420 / 7$ weeks and beyond [1].

Late preterm infants have been termed The Great Imposters. Infants delivered at late preterm and early term gestational age are at disproportionately higher risk for immediate complications like Respiratory Distress Syndrome (RDS), Transient Tachypnea of Newborn (TTNB), neonatal sepsis, neonatal jaundice, hypoglycemia, Neonatal Intensive Care Unit (NICU) admission [2,3], prolonged hospitalization and re-hospitalisation [4,5], major morbidity, death, and increased health care utilization [6]. The long term complications include poor growth, learning disorder, cerebral palsy, development of psychiatric disorders, poor fetal growth and experience mental and physical developmental delay [7-9]. Late preterm and early term may occur as a result of

- Spontaneous /idiopathic early term or preterm labor

- Prelabor Spontaneous Rupture of Chorioamniotic Membranes (PPROM)

- Maternal and fetal conditions needing an iatrogenic delivery or

- Delivery for non-indicated reasons like patient or provider preference [10]

With the time period there have been gradual increases in the prevalence of late preterm and early term delivery in United States. In 1995 , the proportions of deliveries at 34 to 36 , and 37 to 38 weeks were $6.2 \%$, and $20.6 \%$, respectively which increased to $7.5 \%$, and $29.7 \%$, respectively in 2008. The absolute increases in deliveries in the late preterm (34-36 weeks) and early term delivery $1.3 \%$ and $9.1 \%$ [11]. The cause of this change has been suggested because of frequent obstetric intervention leading to increase in the proportion of deliveries in one gestational age window with simultaneous reduction of another. The increase in delivery at 37 to 38 weeks' gestational age is the result of a shift away from delivery at 39 weeks or greater gestational age [12]. A recent meta-analysis conducted by Lisonkova et al on deliveries in the United States, Canada, and 26 other European countries found that the prevalence of late preterm birth ranged from $4.4 \%$ to $10.0 \%[13]$

\section{Adverse Infant Outcomes Associated With Delivery from 34 to 38 Weeks' Gestation}

\section{Respiratory Disorders}

The varied respiratory disorders in this unique group of population can be varied and often includes Transient Tachypnea of The Newborn (TTNB), Respiratory Distress Syndrome (RDS), Persistent Pulmonary Hypertension (PPHN), and rarely apnea [14-17]. Of the affected babies, the incidence of respiratory distress requiring mechanical ventilation corresponded with the degree of prematurity: $3.3 \%$ of late preterm infants born at 34 weeks' gestation, $1.7 \%$ at 35 weeks, and $0.8 \%$ at 36 weeks' gestation [18], showing that with decrease in gestational age of delivery the respiratory morbidity increases [19]. The immature lung structure present before moderate term may be associated functionally with delayed intrapulmonary fluid absorption, surfactant insufficiency, and inefficient gas exchange leading to TTNB and RDS $[6,20]$. Colin et al concluded that preterm birth, even without any significant neonatal respiratory disease, can still have adverse effects on lung growth and development, leading to reduced pulmonary function and increased morbidity [21]. Ghartey et al. reported that the rates of RDS, transient TTN, pneumonia, surfactant use, and ventilation use were more at 37 weeks compared with 39 weeks and showed inverse relationship with increase in gestation [22]. Although majority of these neonates have transient respiratory issues, but few neonates develop persistent pulmonary hypertension of the neonate (PPHN) or severe hypoxic respiratory failure, conditions requiring advanced respiratory support therapies such as nitric oxide, high-frequency ventilation, and Extracorporeal Membrane Oxygenation (ECMO) [17,23]. In long term these neonates have higher risk of respiratory illnesses and re-hospitalizations in infancy and early childhood [24,25]. The detail review on the respiratory morbidity can be studied elsewhere [26].

\section{Neurologic and Metabolic Issues}

Late preterm and early term infants are generally considered to be low-risk groups for neurological and metabolic problems but they are important group who are prone to develop various neurological morbidities in long term. The frequency of GMH-IVH is very low in late preterm and early term infants as there is involution of germinal matrix by 34 weeks of gestation $[18,27]$. Relative to GMH-IVH there are even fewer data on Periventricular Leukomalacia (PVL) in late preterm and early term infants $[6,18,28]$. There are currently no specific recommendations for screening and neuro imaging of late preterm, or early term infants. The most commonly seen clinical problem in late preterm and early term infants is feeding difficulties. In a systematic review conducted by Teune et al. on the medical and developmental short-term and long-term outcomes of late preterm 
infants, showed that $34 \%$ of these late preterm infants had feeding difficulties and was the most common short-term morbidity encountered by this cohort [27]. Feeding issues of these late preterm infants are extensions of maturational development of feeding abilities of the moderately preterm infant [28]. These vulnerable groups are also prone for metabolic complications like hypoglycemia, hypothermia, jaundice, immunologic problems, increased susceptibility to infection hypocalcemia and polycythaemia. The detail review on the neurological and metabolic issues can be studied in various excellent reviews [29].

\section{Long-Term Outcomes}

Between 35 and 41 weeks, there is a 5 -fold increase in brain volume and this continued active brain maturation occurs during the last few weeks of gestation because of neurogenesis, synaptogenesis, and dendritic arborization. These processes of neural development get interrupted by delivery as the infant is removed the natural protective environment of the uterus [30]. These late preterm and early term infants have more subtle findings of language delay, attention deficits, lower intelligence, behavioural problems, developmental disability, school failure, and academic achievement issues [8,31-34]. The detail review on the long term outcome of these infants can be read elsewhere [35].

\section{Hospital Readmissions}

Readmission rates of late preterm infants are 1.5 to 3 times that of term infants $[5,33,36]$. The most common causes for re-hospitalisation within 2 weeks of life includes jaundice, infection and feeding problems [5,37]. The cause of recurrent hospitalization after two weeks of age included bronchiolitis, pneumonia, fever and gastrointestinal. The incidence of readmission decrease with increases in gestational age $[38,39]$.

\section{Jaundice and Kernicterus}

The early discharge of the late preterm and early term places these neonates for higher adverse effect of neonatal jaundice. The high rates for jaundice admissions in late preterm and early term infants can be understood by considering underlying pathophysiology. Late preterm infants and early terms have a decreased capacity to handle unconjugated bilirubin, decreased hepatic uptake, decreased Uridinediphosphoglucuronate Glucuronosyl Transferase (UGT) activity, and increased enterohepatic circulation, delayed postnatal maturation of hepatic bilirubin uptake and bilirubin conjugation, placing them at higher risk for neonatal jaundice. This hepatic immaturity is added by delayed lactogenesis seen in mothers of these infants [40-42]. These all factors add up leading to high chances of jaundice and neonatal jaundice is most common cause of readmission in these infants within two weeks of life [5].

\section{Future directions}

Maturation is a continuous process with no specific goals to be achieved. When the late preterm and early term infants are compared with those born before 34 weeks of gestation, these infants are at lower risks for numerous medical problems, but, compared with those born at 39 and 40 weeks' gestation, they are at higher risks for various morbidity and mortality [43-45]. There are many field of investigation and research including cardiovascular and pulmonary systems, nervous system, metabolic, nutrition, breastfeeding and lactation, immunology and sepsis, renal and genitourinary systems, development pharmacology [46,47].

\section{References}

1. Cunningham FG, Leveno KJ, Bloom SL, Hauth J C, Rouse D J, et al. (2010) Williams obstetrics. 23rdedition. New York: McGraw-Hill: 820831.

2. Gilbert WM, Nesbitt TS, Danielsen B (2003) The cost of prematurity: quantification by gestational age and birth weight. Obstet Gynecol 102: 488-492.

3. Clements KM, Barfield WD, Ayadi MF, Wilber N (2007) Preterm birthassociated cost of early intervention services: an analysis by gestational age. Pediatrics 119: e866-874.

4. Petrou S, Mehta Z, Hockley C, Cook-Mozaffari P, Henderson J, et al. (2003) The impact of preterm birth on hospital inpatient admissions and costs during the first 5 years of life. Pediatrics 112: 1290-1297.

5. Escobar GJ, Joffe S, Gardner MN, Armstrong MA, Folck BF, et al. (1999) Rehospitalization in the first two weeks after discharge from the neonatal intensive care unit. Pediatrics 104: e2.

6. Wang ML, Dorer DJ, Fleming MP, Catlin EA (2004) Clinical outcomes of near-term infants. Pediatrics 114: 372-376.

7. Bastek JA, Sammel MD, Paré E, Srinivas SK, Posencheg MA, et al. (2008) Adverse neonatal outcomes: examining the risks between preterm, late preterm, and term infants. Am J Obstet Gynecol 199: 367.

8. Morse SB, Zheng H, Tang Y, Roth J (2009) Early school-age outcomes of late preterm infants. Pediatrics 123: e622-629.

9. Rogers CE, Lenze SN, Luby JL (2013) Late preterm birth, maternal depression, and risk of preschool psychiatric disorders. J Am Acad Child Adolesc Psychiatry 52: 309-318.

10. Spong CY, Mercer BM, D'alton M, Kilpatrick S, Blackwell S, et al. (2011) Timing of indicated late-preterm and early-term birth. Obstet Gynecol 118: 323-333.

11. Ananth CV, Friedman AM, Gyamfi-Bannerman C (2013) Epidemiology of moderate preterm, late preterm and early term delivery. Clin Perinatol 40: 601-610.

12. Baroutis G, Mousiolis A, Mesogitis S, Costalos C, Antsaklis A (2013) Preterm birth trends in Greece, 1980-2008: a rising concern. Acta Obstet Gynecol Scand 92: 575-582.

13. Lisonkova S, Sabr Y, Butler B, Joseph KS (2012) International comparisons of preterm birth: higher rates of late preterm birth are associated with lower rates of stillbirth and neonatal death. BJOG 119: 1630-1639.

14. Consortium on Safe Labor, Hibbard JU, Wilkins I, Sun L, Gregory K, et al. (2010) Respiratory morbidity in late preterm births. JAMA 304: 419-425.

15. Roth-Kleiner M, Wagner BP, Bachmann D, Pfenninger J (2003) Respiratory distress syndrome in near-term babies after caesarean section. Swiss Med Wkly 133: 283-288.

16. Hernández-Díaz S, Van Marter LJ, Werler MM, Louik C, Mitchell AA (2007) Risk factors for persistent pulmonary hypertension of the newborn. Pediatrics 120: e272-282.

17. Keszler M, Carbone MT, Cox C, Schumacher RE (1992) Severe respiratory failure after elective repeat cesarean delivery: a potentially preventable condition leading to extracorporeal membrane oxygenation. Pediatrics 89: 670-672.

18. McIntire DD, Leveno KJ (2008) Neonatal mortality and morbidity rates in late preterm births compared with births at term. Obstet Gynecol 111: $35-41$.

19. De Luca R, Boulvain M, Irion O, Berner M, Pfister RE (2009) Incidence of early neonatal mortality and morbidity after late-preterm and term cesarean delivery. Pediatrics 123: e1064-1071.

20. Engle WA, Tomashek KM, Wallman C; Committee on Fetus and Newborn, American Academy of Pediatrics (2007) "Late-preterm" infants: a population at risk. Pediatrics 120: 1390-1401. 
Citation: Kumar C, Sharma D, Pandita A (2014) Late Preterm and Early Term Neonates: A New Group of High Risk Newborn in Neonatology with Varied Complications. J Neonatal Biol 3: E-112. doi:10.4172/2167-0897.1000E-112

Page 3 of 3

21. Colin AA, McEvoy C, Castile RG (2010) Respiratory morbidity and lung function in preterm infants of 32 to 36 weeks' gestational age. Pediatrics 126: 115-128.

22. Ghartey K, Coletta J, Lizarraga L, Murphy E, Ananth CV, et al. (2012) Neonatal respiratory morbidity in the early term delivery. Am J Obstet Gynecol 207: 292.

23. Heritage CK, Cunningham MD (1985) Association of elective repeat cesarean delivery and persistent pulmonary hypertension of the newborn. Am J Obstet Gynecol 152: 627-629.

24. Resch B, Paes B (2011) Are late preterm infants as susceptible to RSV infection as full term infants? Early Hum Dev 87 Suppl 1: S47-49.

25. Kotecha S, Kotecha SJ (2012) Long term respiratory outcomes of perinatal lung disease. Semin Fetal Neonatal Med 17: 65-66.

26. Mahoney AD, Jain L (2013) Respiratory disorders in moderately preterm, late preterm, and early term infants. Clin Perinatol 40: 665-678.

27. Teune MJ, Bakhuizen S, Gyamfi Bannerman C, Opmeer BC, van Kaam $\mathrm{AH}$, et al. (2011) A systematic review of severe morbidity in infants born late preterm. Am J Obstet Gynecol 205: 374.

28. Dimitriou G, Fouzas S, Georgakis V, Vervenioti A, Papadopoulos VG, et al. (2010) Determinants of morbidity in late preterm infants. Early Hum Dev 86: 587-591.

29. Laptook AR (2013) Neurologic and metabolic issues in moderately preterm, late preterm, and early term infants. Clin Perinatol 40: 723-738.

30. Hüppi PS, Warfield S, Kikinis R, Barnes PD, Zientara GP, et al. (1998) Quantitative magnetic resonance imaging of brain development in premature and mature newborns. Ann Neurol 43: 224-235.

31. Gouyon JB, Vintejoux A, Sagot P, Burguet A, Quantin C, et al. (2010) Neonatal outcome associated with singleton birth at 34-41 weeks of gestation. Int J Epidemiol 39: 769-776.

32. Escobar GJ, Clark RH, Greene JD (2006) Short-term outcomes of infants born at 35 and 36 weeks gestation: we need to ask more questions. Semin Perinatol 30: 28-33.

33. McLaurin KK, Hall CB, Jackson EA, Owens OV, Mahadevia PJ (2009) Persistence of morbidity and cost differences between late-preterm and term infants during the first year of life. Pediatrics 123: 653-659.

34. MacKay DF, Smith GC, Dobbie R, Pell JP (2010) Gestational age at delivery and special educational need: retrospective cohort study of 407,503 schoolchildren. PLoS Med 7: e1000289.
35. Vohr B (2013) Long-term outcomes of moderately preterm, late preterm, and early term infants. Clin Perinatol 40: 739-751.

36. Martens PJ, Derksen S, Gupta S (2004) Predictors of hospital readmission of Manitoba newborns within six weeks postbirth discharge: a population-based study. Pediatrics 114: 708-713.

37. Oddie SJ, Hammal D, Richmond S, Parker L (2005) Early discharge and readmission to hospital in the first month of life in the Northern Region of the UK during 1998: a case cohort study. Arch Dis Child 90: 119-124.

38. Jain S, Cheng J (2006) Emergency department visits and rehospitalizations in late preterm infants. Clin Perinatol 33: 935-945.

39. Tomashek KM, Shapiro-Mendoza CK, Weiss J, Kotelchuck M, Barfield W, et al. (2006) Early discharge among late preterm and term newborns and risk of neonatal morbidity. Semin Perinatol 30: 61-68.

40. Bhutani VK, Johnson L (2006) Kernicterus in late preterm infants cared for as term healthy infants. Semin Perinatol 30: 89-97.

41. Kaplan M, Muraca M, Vreman HJ, Hammerman C, Vilei MT, et al. (2005) Neonatal bilirubin production-conjugation imbalance: effect of glucose-6-phosphate dehydrogenase deficiency and borderline prematurity. Arch Dis Child Fetal Neonatal Ed 90: F123-127.

42. Cregan MD, De Mello TR, Kershaw D, McDougall K, Hartmann PE (2002) Initiation of lactation in women after preterm delivery. Acta Obstet Gynecol Scand 81: 870-877.

43. Reddy UM, Bettegowda VR, Dias T, Yamada-Kushnir T, Ko CW, et al. (2011) Term pregnancy: a period of heterogeneous risk for infant mortality. Obstet Gynecol 117: 1279-1287.

44. Bailit JL, Gregory KD, Reddy UM, Gonzalez-Quintero VH, Hibbard JU, et al. (2010) Maternal and neonatal outcomes by labor onset type and gestational age. Am J Obstet Gynecol 202: 245.

45. Tita AT, Landon MB, Spong CY, Lai Y, Leveno KJ, et al. (2009) Timing of elective repeat cesarean delivery at term and neonatal outcomes. $\mathrm{N}$ Engl J Med 360: 111-120.

46. Raju TN (2013) Moderately preterm, late preterm and early term infants: research needs. Clin Perinatol 40: 791-797.

47. Raju TN, Higgins RD, Stark AR, et al. (2006) Optimizing care and outcome for late-preterm(near-term) infants: a summary of the workshop sponsored by the National Institute of Child Health and Human Development. Pediatrics 118: 1207-1214. 